\title{
ANALISIS PENGARUH KUALITAS PELAYANAN DAN DISIPLIN KERJA KARYAWAN TERHADAP KEPUASAN PASIEN ASKES DI PT ASKES KEDIRI
}

\author{
Yogi Yunanto \\ Dosen Universitas Kadiri - Email: yogi_yunanto@yahoo.com
}

\begin{abstract}
This research is motivated researcher observations and experiences, especially that of PT Askes Kediri Askes Patients who are less sensitive in terms of quality of service and low sense of employee discipline in obeying the rules. As a result, many patients who are less conscious and lazy to perform administrative activities.

The problem of this study is (1) Is the quality of health care insurance in effect on patients' satisfaction, PT Askes Kediri? (2) Is the employee disciplinary effect on patient satisfaction in PT Askes Kediri? (3) Is the quality of service and employee discipline effect on patient satisfaction in PT Askes Kediri?

This study used a qualitative approach to formulating a hypothesis, then the hypothesis will be tested using a quantitative approach. Where the data obtained will be calculated using the formula and test the statistical analisisa

Conclusion The results of this study were (1) Variable quality of service (X1) to simultaneously deliver significant influence on patient satisfaction in PT Askes kediri with a probability value of b1 is 0.017 less than 0.05 . (2) Variable discipline employees (X2) simultaneously providing significant influence on patient satisfaction in PT Askes Kediri with a probability value of b2 is 0.031 less than 0.05 . (3) Variable quality of service (X1) has a regression coefficient $(\beta)$ for $=0.149$, employee discipline (X2) is 0.123 , thus it can be said that the service quality variable (X1) has a dominant influence on patient satisfaction in PT Askes Kediri.Conclusions based on these results, it is recommended: (1) the principal purpose of the application quality of service and employee discipline is to give satisfaction to the patient. Therefore, employees should always put quality of service and employee discipline. (2) the employee must be continuously examined, to prove whether the quality of care and discipline works are in accordance with the applicable rules.
\end{abstract}

Keywords: Quality of Service, Employee Discipline, Patient Satisfaction.

\section{PENDAHULUAN}

Pelayanan dan disiplin kerja karyawan asuransi kesehatan yang berkualitas merupakan salah satu kebutuhan dasar yang diperlukan setiap orang dan disiplin kerja karyawan asuransi kesehatan merupakan salah satu pendukung peningkatan kualitas pelayanan. askes sebagai salah satu pusat pelayanan kesehatan dipandang mampu memberikan atau memenuhi kebutuhan kesehatan masyarakat. askes juga mempunyai peran yang paling luas dalam hubungan dengan aspek fisik dan tipe pelayanan Reliability (kehandalan), Responsiveness (responsif), Tangibles (fasilitas fisik), Crebility (Kreadibilitas), Competence (kompeten) 
Acces (Akses), Courtesy (Kesopanan), Communication (Komunikasi), Understanding The customer (Memahami pelanggan), Security (Keamanan) disinilah letak permasalahan, karena dalam praktek sehari-hari penyelenggaraan pelayanan kesehatan dan disiplin kerja karyawan, termasuk kualitas pelayanan karyawan askes yang sesuai dengan kebutuhan pasien tidaklah mudah. Tidak heran bila saat ini banyak ditemukan keluhan pasien terhadap kualitas pelayanan dan disiplin kerja karyawan askes bagi setiap peserta dan pelayan kesehatan yang diselenggarakan harus dapat memuaskan para pemakai jasa dengan tata cara penyelenggaraan sesuai dengan kode etik serta standar yang ditetapkan Fajar (2008;187). Asuransi kesehatan yang diperlukan untuk mengendalikan biaya kesehatan keluarga meliputi rawat inap, rawat jalan, rawat bersalin, dan rawat gigi, jika kepala keluarga karyawan, umumnya asuransi kesehatannya sudah ditangung oleh perusahaannya tempatnya bekerja Sulastomo (2003;40). Pada kasus-kasus tertentu, biaya kesehatan melebihi batas manfaat yang diperjanjikan sehingga selisihnya harus ditanggung oleh pasien. Sebagai salah satu cara untuk mengatasi hal tersebut, dapat dipilih produk asuransi kesehatan yang bersifat santunan harian ( cash plan). Produk asuransi tersedia sebagai manfaat tambahan pada asuransi kematian berjangka, baik perseorangan maupun per keluarga. Didin dkk $(2009 ; 12)$

Berdasarkan hasil pra penelitian yang dilakukan oleh peneliti pada tanggal 30 Agustus sampai tanggal 4 September 2013 di kantor askes kediri terhadap 15 pasien asuransi kesehatan, di dapatkan hasil surve tabel 1

Tabel 1 Kepuasan peserta terhadap kualitas pelayanan Asuransi Kesehatan

di kantor askes Kediri pada tanggal 30 Agustus sampai 4 September 2013

\begin{tabular}{|l|l|l|l|}
\hline No & Indikator & Jumlah & Prosentase \\
\hline 1 & Pasien vang puas & 6 & $40 \%$ \\
\hline 2 & Pasien yang tidak puas & 9 & $60 \%$ \\
\hline Jumlah & $\mathbf{1 5}$ & $\mathbf{1 0 0 \%}$ \\
\hline
\end{tabular}

Dari data di atas terlihat bahwa angka pasien tidak puas $60 \%$

Askes merupakan salah satu unit pelayanan rawat jalan, rawat inap dan pelayanan pasien asuransi kesehatan. Data yang di peroleh dari kantor askes di dapat mulai bulan Januari 2013 ke bulan Februari 2013 pasien asuransi kesehatan menunjukan penurunan, pada bulan Maret sampai bulan Mei 2013 pasien Askes menunjukan kenaikan, pada bulan Juni sampe dengan bulan Agustus pasien askes menunjukan kenaikan. Data jumlah pasien rawat jalan dan rawat inap dan pelayanan pasien Asuransi Kesehatan di PT askes Kediri Tahun 2013.

Tabel 2 Jumlah Pasien asuransi kesehatan di PT askes Kediri bulan Januari-Agustus

Tahun 2013

\begin{tabular}{|c|c|l|l|c|c|c|c|c|}
\hline \multirow{2}{*}{$\begin{array}{c}\text { Jumlah } \\
\text { Docian }\end{array}$} & \multicolumn{70}{|c|}{ Bulan } \\
\cline { 2 - 9 } Total & Januari & February & Maret & April & Mei & Juni & Juli & Agustus \\
\hline
\end{tabular}

Sumber : Data dari PT askes Kediri Tahun 2013

Pasien yang melakukan rawat inap atau rawat jalan memiliki frekuensi lebih banyak untuk berinteraksi dengan institusi tempat pelayanan kesehatan yang dapat memberikan kepuasan terhadap pasien, pelayanan yang di berikan oleh karyawan asuransi kesehatan yang 
ada di tempat kantor askes, menyatakan bahwa pasien akan merasa puas terhadap pelayanan apabila karyawan memiliki minat terhadap orang lain, menerima pasien tanpa membedakan golongan, pangkat, latar belakang sosial ekonomi dan budaya sehingga memandang pasien sebagai pribadi yang utuh. Askes memberikan tawaran pemilik bentuk-bentuk Asuransi Kesehatan seperti indemnity system, maupun managed care system serta memberikan 3 (tiga) bentuk asuransi kesehatan yaitu: Social health insurance (asuransi kesehatan sosial), Private voluntary health insurance (asuransi kesehatan komersial), Regulated private health insurance asuransi kesehatan sukarela dengan regulasi, Sulastomo $(2003 ; 194)$

Tingkat kepuasan pasien terhadap pelayanan dan disiplin kerja karyawan merupakan faktor yang penting dalam mengembangkan suatu sistem penyediaan pelayanan yang sesuai dengan kebutuhan pasien. Selain itu faktor internal seperti aspek dokter, aspek perawat, kecepatan sarana penunjang, maupun sarana dan prasarana serta aspek eksternal yang meliputi faktor geografis dan faktor pasien juga mempengaruhi kepuasan Fajar (2008;96). Peningkat kualitas pelayanan dan disiplin kerja karyawan pada pasien asuransi kesehatan sangat perlu diperhatikan kebutuhannya, Kualitas pelayanan ini meliputi Tangibles, Reliability, Responsiveness, Assurance, Empathy supriyanto $(2010 ; 58)$ Selain itu pelayanan yang diberikan kepada pasien agar mendapatkan kepuasan terhadap pelayanan kesehatan yang diberikan yaitu akses, hal yang menyenangkan, komunikasi, mutu pelayanan kesehatan yang diterima, pelayanan personal, fasilitas Wijono (2008; 53), sehinga minat masyarakat untuk menggunakan fasilitas kesehatan seperti Instalasi rawat jalan, rawat inap, daftar pasien askes sebagai pemberi pelayanan kesehatan menjadi meningkat. Disipilin kerja kryawan dalam memberikan pelayanan asuransi kesehatan harus bersikap profesional baik terhadap pasien umum maupun peserta Askes. karyawan dituntut memberikan pelayanan yang komprehensif dan professional dalam memberikan pelayanan. Hal inilah yang menarik bagi peneliti untuk malakukan panelitian tentang Analisis Pengaruh Kualitas Pelayanan Dan Disiplin Kerja Karyawan Terhadap Kepuasan Pasien Askes Di PT Askes Kediri.

\section{METODE PENELITIAN}

\section{Rancangan atau Desain Penelitian}

Desain penelitian adalah Regresi linier jenis penelitian yang menekankan pada waktu pengukuran atau observasi data variabel independen (kualitas pelayanan dan disiplin kerja karyawan asuransi kesehatan) dan dependen (kepuasan) hanya satu kali, pada satu saat.

\section{Pendekatan penelitian}

Pendekatan penelitian yang digunakan dalam penelitian ini adalah pendekatan kuantitatif dengan merumuskan hipotesis, selanjutnya hipotesis tersebut akan diuji dengan menggunakan pendekatan kuantitatif. Dimana data-data yang diperoleh akan dihitung dengan menggunakan rumus dan uji dengan analisis statistic

Instrumen pengumpulan data yang digunakan dalam penelitian ini adalah beberapa kuesioner yaitu peneliti mengumpulkan data secara formal kepada subyek untuk menjawab pertanyaan secara tertulis. Data umum memuat pertanyaan mengenai data demografi responden yang terdiri dari 4 pertanyaan yaitu : jenis kelamin, umur, pendidikan, pekerjaan. Data khusus memuat pertanyaan mengenai variabel penelitian yaitu variabel kualitas pelayanan dan disiplin 
kerja karyawan asuransi kesehatan dan kepuasan pasien, dengan kuesioner yang telah disediakan dengan jumlah 10 pertanyaan untuk variabel kualitas pelayanan dan disiplin kerja karyawan asuransi kesehatan dan 10 pertanyaan untuk variabel kepuasan pasien, jadi jumlah seluruhnya adalah 30 pertanyaan.

Peneliti mengadakan pengumpulan data. Data yang terkumpul lalu diolah dengan menggunakan skoring.

$$
\text { Skor }=\underset{\text { Jumlah item pertanyaan }}{\text { Jumlah jawaban yang benar }} \mathrm{X} \mathrm{100 \%}
$$

\section{Proses Pengumpulan Data}

Setelah peneliti mendapatkan ijin dari Direktur PT Askes Kediri, peneliti mengadakan pendekatan kepada pasien askes di PTAskes Kediri. Pengumpulan data yang digunakan dalam penelitian ini adalah dengan memberikan kuesioner dan menguji validitas dan reabilitasnya. Data yang telah terkumpul kemudian diolah dengan menggunakan skoring.

\section{HASIL PENELITIAN, ANALISIS, DAN PEMBAHASAN}

\section{Hasil Penelitian}

\section{A. Data Umum}

\section{Jenis Kelamin}

Tabel 3. Karakteristik Responden Menurut Jenis kelamin

Tabel 3

Karakteristik Responden Menurut Jenis kelamin

\begin{tabular}{|l|l|l|}
\hline Jenis Kelamin & Jumlah & Persentase \\
\hline Laki-laki & 20 & $50 \%$ \\
\hline Perempuan & 20 & $50 \%$ \\
\hline Total & 40 & $100 \%$ \\
\hline
\end{tabular}

Sumber : Data primer yang sudah diolah

Berdasarkan tabel 3 diketahui bahwa responden jenis kelamin laki-laki sebanyak 20 orang $(50 \%)$, jenis kelamin perempuan sebanyak 20 orang (50\%). Dengan demikian, jumlah responden laki-laki dan perempuan sama besarnya.

\section{Pekerjaan}

Tabel 4.Karakteristik Responden Menurut Pekerjaan

Karakteristik program pekerjaan yang diteliti berdasarkan hasil penyebaran kuisioner pada pasien askes diketahui sebagai berikut :

Tabel 4

Karakteristik Responden Menurut Pekerjaan

\begin{tabular}{|l|l|l|}
\hline Pekerjaan & Jumlah & Persentase \\
\hline Bekerja & 20 & $50 \%$ \\
\hline Tidak Bekerja & 10 & $25 \%$ \\
\hline
\end{tabular}




\begin{tabular}{|l|l|l|}
\hline Mahasiswa & 10 & $25 \%$ \\
\hline Total & 40 & $100 \%$ \\
\hline
\end{tabular}

Sumber : Data primer yang sudah diolah

Berdasarkan tabel 4 diketahui bahwa responden dari bekerja sebanyak 20 orang (50\%), tidak bekerja sebanyak 10 orang (25\%), mahasiswa sebanyak 10 orang (25\%). Dengan demikian, jumlah responden bekerja merupakan kelompok yang paling besar.

\section{Umur}

Karakteristik umur yang diteliti berdasarkan hasil penyebaran kuisioner pada pasien askes diketahui sebagai berikut :

Tabel 5

Karakteristik Responden Menurut Umur

\begin{tabular}{|l|l|l|}
\hline Umur & Jumlah & Persentase \\
\hline $20-30$ tahun & 5 & $12,5 \%$ \\
\hline $31-40$ tahun & 10 & $25 \%$ \\
\hline $41-50$ tahun & 15 & $37,5 \%$ \\
\hline$>50$ tahun & 10 & $25 \%$ \\
\hline Total & 40 & $100 \%$ \\
\hline
\end{tabular}

Sumber: Data primer yang sudah diolah

Berdasarkan tabel 5 diketahui bahwa responden dari umur 20 - 30 tahun sebanyak 5 orang (12,5\%), umur 31 - 40 tahun sebanyak 10 orang (25\%), umur 41- 50 tahun sebanyak 15 orang $(37,5 \%)$, umur $>50$ tahun sebanyak 10 orang $(25 \%)$, Dengan demikian, jumlah umur 41- 50 tahun merupakan kelompok yang paling besar.

\section{Pendidikan}

Karakteristik pendidikan yang diteliti berdasarkan hasil penyebaran kuisioner pada pasien askes diketahui sebagai berikut :

Tabel 6

Karakteristik Responden Menurut Pendidikan

\begin{tabular}{|l|l|l}
\hline Pendidikan & Jumlah & Persentase \\
\hline SD & - & - \\
\hline SLTP & 5 & $12,5 \%$ \\
\hline SLTA & 20 & $50 \%$ \\
\hline AKADEMI / PT & 15 & $37,5 \%$ \\
\hline TOTAL & 40 & $100 \%$ \\
\hline
\end{tabular}

Sumber : Data primer yang sudah diolah 
Berdasarkan tabel 6 diketahui bahwa responden pendidikan SD dan SLTP sebanyak 5 orang (12,5\%), pendidikan SLTA sebanyak 20 orang (50\%), pendidikan AKADEMI / PT sebanyak 15 orang (37,5\%). Dengan demikian, jumlah pendidikan SLTA merupakan kelompok yang paling besar.

\section{B. Data Khusus}

\section{Kualitas Pelayanan}

Tabel 7 Karakteristik Responden Kualitas Pelayanan

\begin{tabular}{|l|l|l|l|}
\hline No & $\begin{array}{l}\text { K u a l i t a s } \\
\text { pelayanan }\end{array}$ & Frekuensi & Prosentase \\
\hline 1. & Sangat puas & 4 & 10 \\
\hline 2. & Puas & 14 & $35 \%$ \\
\hline 3. & Cukup puas & 15 & $37,5 \%$ \\
\hline 4. & Tidak puas & 6 & 15 \\
\hline 5. & $\begin{array}{l}\text { Sangat tidak } \\
\text { puas }\end{array}$ & 1 & $2,5 \%$ \\
\hline 6. & JUMLAH & 40 & 100 \\
\hline
\end{tabular}

Sumber : Data primer diolah, Tahun 2013

Berdasarkan tabel 7dapat diketahui bahwa bahwa 15 responden $(37,5 \%)$ cukup puas dengan kualitas pelayanan.

\section{Disiplin Kerja Karyawaan}

Tabel 8 Karakteristik Responden Menurut Kerja Karyawan

\begin{tabular}{|l|l|l|l|}
\hline No & $\begin{array}{c}\text { Disiplin kerja } \\
\text { karyawan }\end{array}$ & Frekuensi & Prosentase \\
\hline 1. & Sangat puas & 1 & $2,5 \%$ \\
\hline 2. & Puas & 10 & $25 \%$ \\
\hline 3. & Cukup puas & 25 & $62,5 \%$ \\
\hline 4. & Tidak puas & 4 & $10 \%$ \\
\hline 5. & Sangat tidak puas & 0 & 0 \\
\hline 6. & Jumlah & 40 & 100 \\
\hline
\end{tabular}

Sumber : Data primer diolah, Tahun 2013

Berdasarkan tabel 8 dapat diketahui bahwa 25 responden $(62,5 \%)$ cukup puas dengan kerja karyawan.

\section{Kepuasan Pasien}

Tabel 9 Karakteristik Responden Menurut Kepuasan Pasien

\begin{tabular}{|l|l|l|l|}
\hline No & $\begin{array}{c}\text { Kepuasan } \\
\text { pasien }\end{array}$ & Frekuensi & Prosentase \\
\hline 1. & Sangat puas & 19 & $47,5 \%$ \\
\hline 2. & Puas & 13 & $32,5 \%$ \\
\hline 3. & Cukup puas & 6 & $15 \%$ \\
\hline
\end{tabular}




\begin{tabular}{|l|l|l|l|}
\hline 4. & Tidak puas & 0 & $0 \%$ \\
\hline 5. & $\begin{array}{l}\text { Sangat } \\
\text { tidak }\end{array}$ & 2 & $5 \%$ \\
\hline 6. & Jumlah & 40 & $100 \%$ \\
\hline
\end{tabular}

Sumber : Data primer diolah, Tahun 2013

Berdasarkan tabel 9 dapat diketahui bahwa 19 responden $(47,5 \%)$ mempunyai tingkat kepuasan sangat puas.

\section{Analisis}

Perhitungan statistik dalam analisis regresi dijelaskan pada Tabel berikut ini.

\section{Tabel 10}

\section{Hasil Analisis Regresi Linear Pengaruh Variabel Bebas (X)}

Terhadap Variabel Terikat (Y)

Coefficients $^{\mathrm{a}}$

\begin{tabular}{|c|c|c|c|c|c|c|c|c|c|}
\hline & & $\begin{array}{r}\text { Unsté } \\
\text { مـ }\end{array}$ & $\begin{array}{l}\text { dardized } \\
\text { icients }\end{array}$ & $\begin{array}{l}\text { Standardized } \\
\text { Coefficients }\end{array}$ & & & & lations & \\
\hline & Model & B & Std. Error & Beta & $\mathrm{T}$ & Sig. & $\begin{array}{l}\text { Zero- } \\
\text { order }\end{array}$ & Partial & Part \\
\hline & (Constant) & 8.929 & 7.657 & & 1.166 & .251 & & & \\
\hline 1 & Kualltas & .399 & .159 & .358 & 2.510 & .017 & .417 & .381 & .352 \\
\hline & Keria & .452 & .202 & .319 & 2.238 & .031 & .386 & .345 & .314 \\
\hline
\end{tabular}

a. dependent variable: kepuasan pasien

Sumber : Data Tahun 2013

Model persamaan regresi yang dapat dituliskan dari hasil tersebut dalam bentuk persamaan regresi standardized adalah sebagai berikut :

$$
\mathrm{Y}=8,929+0,358 \mathrm{X}_{1}+0,319 \mathrm{X}_{2}
$$

Persamaan regresi tersebut dapat dijelaskan sebagai berikut :

Dari persamaan tersebut dapat terlihat bahwa keseluruhan variabel bebas (kualitas pelayanan dan disiplin kerja karyawan) berpengaruh positif terhadap kepuasan pasien Berdasarkan persamaan dapat diketahui bahwa variabel bebas yang paling berpengaruh adalah variabel kualitas pelayanan dengan koefisien 0,358, sedangkan variabel yang berpengaruh paling rendah yaitu variabel disiplin kerja karyawan dengan nilai koefisien 0,319.

\section{Uji hipotesis}

Dalam penelitian ini terdapat dua hipotesis yang akan di uji, untuk menguji hipotesis dapat dilakukan uji t dan uji f. Adapun uji hipotesis tersebut adalah sebagai berikut:

\section{a. Uji t Digunakan untuk pengujian Hipotesis I ( Masalah I )}

Dalam penelitian ini dilakukan uji t untuk mengetahui pengaruh secara parsial antara variabel bebas $(\mathrm{X})$ dengan variabel terikat $(\mathrm{Y})$. Uji t dilakukan untuk menjawab rumusan 
masalah mengenai ada tidaknya pengaruh signifikan kualitas pelayanan $(\mathrm{X})$ dan disiplin kerja karyawan (X ) terhadap kepuasan pasien (Y). Adapun hasil uji t seperti tabel 11 berikut:

\section{Tabel 11}

\section{Ringkasan Hasil Uji Regresi Linear Pengaruh}

\section{Variabel Bebas (X) Terhadap Variabel Terikat (Y) Secara Parsial} Coefficients $^{\mathrm{a}}$

\begin{tabular}{|c|c|c|c|c|c|c|c|c|c|}
\hline & \multirow{2}{*}{ Model } & \multicolumn{2}{|c|}{$\begin{array}{c}\text { Unstandardized } \\
\text { Coefficients }\end{array}$} & \multirow{2}{*}{$\begin{array}{c}\text { Standardized } \\
\text { Coefficients } \\
\text { Beta }\end{array}$} & \multirow{2}{*}{$\mathrm{T}$} & \multirow{2}{*}{ Sig. } & \multicolumn{3}{|c|}{ Correlations } \\
\hline & & B & Std. Error & & & & $\begin{array}{l}\text { Zero- } \\
\text { order }\end{array}$ & Partial & Part \\
\hline \multirow{3}{*}{1} & (Constant) & 8.929 & 7.657 & & 1.166 & .251 & & & \\
\hline & $\begin{array}{l}\mathrm{K} \text { u a I i t a } \mathrm{s} \\
\text { Pelayanan }\end{array}$ & .399 & .159 & .358 & 2.510 & .017 & 417 & .381 & .352 \\
\hline & Disiplin Kerja & .452 & .202 & .319 & 2.238 & .031 & .386 & .345 & .314 \\
\hline
\end{tabular}

a. Dependent Variable: Kepuasan pasien

Sumber : Data primer diolah, Tahun 2013

\section{Pengujian Hipotesis 1 ( Parsial )}

"Terdapat pengaruh yang signifikan kualitas pelayanan terhadap kepuasan pasien di PT askes kediri”"

Berdasarkan perhitungan dari analisis regresi pada tabel 11 dapat diketahui bahwa nilai $\mathrm{t}_{\text {hitung }} \mathrm{H}$ diterima pelayanan terhadap kepuasan pasien di PT askes kediri

\section{Pengujian Hipotesis 1 ( Parsial )}

"Terdapat pengaruh yang signifikan disiplin kerja Karyawan terhadap kepuasan pasien di PT askes Kediri”.

Berdasarkan perhitungan dari analisis regresi pada tabel 11 dapat diketahui bahwa Nilai $t_{\text {hitung }}$ sebesar 2.238 dan sig t sebesar 0.031 . Karena sig $\mathrm{t}<0,05(0.031<0,05)$, maka $\mathrm{h}$ diterima yang berarti terdapat pengaruh positif dan signifikan secara parsial disiplin kerja Karyawan terhadap kepuasan pasien di PT askes Kediri.

\section{b. Uji F Digunakan untuk Hipotesis 2 (Masalah ke 2 )}

Uji $\mathrm{F}$ dilakukan untuk mengetahui pengaruh secara bersama-sama atau silmutan variabel bebas $(\mathrm{X})$ dengan variabel terikat $(\mathrm{Y})$. Uji $\mathrm{F}$ dilakukan untuk menjawab rumusan masalah mengenai variabel Kualitas Pelayanan dan Disiplin Kerja Karyawan terhadap kepuasan pasien di PT askes Kediri. Adapun hasil uji F seperti pada tabel 12 berikut : 


\section{Tabel 12}

\section{Ringkasan Hasil Uji Regresi Linear Pengaruh Variabel Bebas (X) Terhadap Variabel Terikat (Y) Secara Simultan \\ ANOVA $^{\text {b }}$}

\begin{tabular}{|c|c|c|c|c|c|c|}
\hline & Model & Sum of Squares & $d f$ & Mean Square & $\mathrm{F}$ & Sig. \\
\hline \multirow{3}{*}{1} & Regression & 370.559 & 2 & 185.280 & 6.931 & $.003^{\mathrm{a}}$ \\
\hline & Residual & 989.041 & 37 & 26.731 & & \\
\hline & Total & 1359.600 & 39 & & & \\
\hline
\end{tabular}

a. Predictors: (Constant), Disiplin Kerja, Kualitas Pelayanan

b. Dependent Variable: Kepuasan Pasien

Sumber : Data primer diolah, Tahun 2013

Model Summaryb

\begin{tabular}{|c|c|c|c|c|c|}
\hline Model & $\mathrm{R}$ & $\mathrm{R}$ Square & Adjusted R Square & $\begin{array}{c}\text { Std. Error of the } \\
\text { Estimate }\end{array}$ & Durbin-Watson \\
\hline 1 & $.522^{\mathrm{a}}$ & .727 & .233 & 5.170 & 2.426 \\
\hline
\end{tabular}

a. Predictors: (Constant), Disiplin Kerja, Kualitas Pelayanan

b. Dependent Variable: Kepuasan Pasien

Sumber : Data primer diolah, Tahun 2013

Berdasarkan hasil uji ANOVA atau $f$ test pada Tabel 12 didapatkan $f$ hitung sebesar 6.931 dengan tingkat signifikansi 0,003. Karena $\mathrm{f}$ hitung $6.931>0,05$ maka dapat dinyatakan bahwa variabel independen yang meliputi kualitas pelayanan (X1) dan disiplin kerja karyawan (X2), secara simultan atau bersama - sama mempengaruhi variabel kepuasan pasien (Y) dan ini membuktikan bahwa variabel tersebut berpengaruh atau signifikan.

Dapat dilihat bahwa $R$ square $=0,727$. Hal ini menunjukan bahwa kualitas pelayanan dan disiplin kerja karyawan secara bersama-sama mempengaruhi kepuasan kerja sebesar 72,7\%, sedangkan sisanya $27,3 \%$, dipengaruhi oleh faktor-faktor lain yang tidak teliti dalam penelitian.

\section{Pengujian Hipotesis 3} Kediri.

"Kualitas pelayanan memiliki pengaruh dominan terhadap kepuasan pasien di PT askes

Untuk menguji hipotesis tersebut dapat diketahui melalui besarnya nilai koefisien regresi $(\beta)$, maka digunakan rumus Zero order $\mathrm{x}$ Beta $\mathrm{x} 100 \%$. Variabel kualitas pelayanan $(\mathrm{X})$ sebesar 0,417 x 0,358 x 100\% =14,9. Variabel disiplin kerja karyawan $(X)$ sebesar 0,386 x 0,319 x $100 \%=12,3$. Hal tersebut juga ditujukan dengan hasil standar dized coefficients yang lebih besar kualitas pelayanan $(0,352)$ dibandingkan dengan kepuasan $(0,316)$ Dengan demikian dapat dikatakan bahwa variabel yang memiliki pengaruh yang dominan terhadap kepuasan pasien di PT askes Kediri. adalah variabel kualitas pelayanan $\left(\mathrm{X}_{1}\right)$. 


\section{Pembahasan}

\section{Pengaruh Kualitas Pelayanan Terhadap Kepuasan pasien}

Pengujian hipotesis 1 menunjukkan adanya pengaruh yang positif dan signifikan antara variabel kualitas pelayanan terhadap kepuasan pasien. Hasil ini menunjukkan bahwa penilaian yang baik mengenai kualitas pelayanan yang sesuai dengan tingkat keinginan pasien akan mendorong pasien untuk melakukan kegiatan yang berhubungan dengan asuransi kesehatan.

Hasil ini menjelaskan bahwa kualitas pelayanan yang mengikuti keinginan pasien akan menghasilkan penilaian konsumen terhadap layanan yang diberikan tersebut. Apabila pelayanan tersebut dapat memuaskan keinginan pasien maka pasien akan memberikan penilaian positif terhadap kualitas pelayanan tersebut. Dengan penilaian tersebut maka pasien akan tetap berkeinginan untuk melakukan kegiatan administrasi tersebut. Hasil ini menjelaskan bahwa pada umumnya pasien dalam melakukan kegiatan asuransi kesehatan akan memperhitungkan kualitas yang diterimanya.

\section{Pengaruh Disiplin Kerja Karyawan Terhadap Kepuasan Pasien}

Disiplin kerja karyawan memiliki pengaruh yang signifikan terhadap kepuasan pasien. Hal ini berarti bahwa pasien menginginkan sikap karyawan yang disiplin terhadap aturan kantor. Dalam penelitian ini pasien yang menilai bahwa karyawan askes mempunyai disiplin yang baik terhadap aturan yang ada. Hipotesis 2 menunjukkan adanya pengaruh yang positif dan signifikan displin kerja karyawan terhadap kepuasan pasien. Hasil ini menunjukkan bahwa disiplin kerja karyawan yang baik akan membantu pasien dalam kegiatan yang berhubungan dengan asuransi kesehatan.

\section{Pengaruh Kualitas Pelayanan dan Disiplin Kerja Karyawan Terhadap Kepuasan Pasien}

Berdasarkan hasil uji ANOVA atau $\mathrm{f}$ test pada didapatkan $\mathrm{f}$ hitung sebesar 6.931 dengan tingkat signifikansi 0,003. sehingga dapat dinyatakan bahwa variabel independen yang meliputi kualitas pelayanan (X1) dan disiplin kerja karyawan (X2), secara simultan atau bersama - sama mempengaruhi variabel kepuasan pasien (Y).

Sebab dalam pengujian hipotesis 1 menunjukkan adanya pengaruh yang positif dan signifikan variabel kualitas pelayanan terhadap kepuasan pasien. Hasil ini menunjukkan bahwa penilaian yang baik mengenai kualitas pelayanan yang sesuai dengan tingkat keinginan pasien akan mendorong pasien untuk melakukan kegiatan asuransi kesehatan. Sedangkan pada hipotesis 2 menunjukkan adanya pengaruh yang positif dan signifikan disiplin kerja karyawan terhadap kepuasan pasien. Hasil ini menunjukkan bahwa disiplin terhadap aturan yang ada akan membantu pasien dalam melakukan kegiatan asuransi kesehatan. Jadi ini atau signifikan terhadap kepuasan pasien.

Hipotesis yang dominan yaitu ditujukan dengan kualitas pelayanan berpengaruh dominan terhadap kepuasan pasien. 
EkoNiKa | Vol. 1, No. 1, April 2016:26 - 37

\section{KESIMPULAN DAN SARAN}

\section{Kesimpulan}

Dari hasil uraian yang telah disebutkan pada bab-bab sebelumnya tentang pengaruh kualitas pelayanan dan disiplin kerja Karyawan terhadap kepuasan pasien di PT askes Kediri, dapat ditarik kesimpulan sebagai berikut :

1. Variabel kualitas pelayanan (X ) secara parsial memberikan pengaruh secara signifikan terhadap kepuasan pasien di PT askes Kediri.

2. Variabel disiplin kerja karyawan $\left(\mathrm{X}_{2}\right)$ secara parsial memberikan pengaruh secara signifikan terhadap kepuasan pasien di PT askes Kediri.

3. Variabel Kualitas pelayanan (X) danVariabel disiplin kerja karyawan (X) secara simultan memberikan pengaruh secara signifikan terhadap kepuasan pasien di PT askes Kediri.

\section{Saran}

Berdasarkan hasil perhitungan yang diperoleh, maka dapat disampaikan saran - saran sebagai berikut :

1. Perlu peranan seorang pemimpin yang aktif terhadap karyawan PT askes Kediri, seperti halnya memberkan perhatian dan bonus terhadap karyawan yang berprestasi karena secara teori ataupun kenyataan hal tersebut sangat mendukung guna meningkatkan kepuasan kerja.

2. Untuk meningkatkan kepuasan pasien, maka karyawan hendaknya memiliki kesadaran diri yang baik atas kedisiplinan dan komunikasi dengan Atasan maupun teman sekerja.

3. Untuk lebih menguatkan semua hipotesis yang terbukti secara empiris diterima, maka perlu dilakukan penelitian - penelitian ulang dalam organisasi yang berbeda dan dalam waktu yang berbeda, agar dapat diperoleh suatu hasil kajian yang termutakhir pada masa - masa yang akan datang. 
EkoNiKa | Vol. 1, No. 1, April 2016:26 - 37

\section{DAFTAR PUSTAKA}

Didin (2009) Solusi Beransuransi. Salamadani Pustaka Semesta Bandung Fajar (2008) Manajemen Pemasaran.Graha Ilmu Yogyakarta

Ferry (2009) Fundamental Keperawatan. EGC Jakarta

Nursalam dan Siti Pariani (2001) Metodologi Riset Keperawatan.

Salemba Medika. Jakarta

Nursalam (2003) Konsep dan Penerapan Metodologi Penelitian Ilmu Keperawatan. Salemba Medika. Jakarta

Nursalam (2007) Manajemen Keperawatan. Salemba Medika Jakarta

Pohan (2007) Jaminan Mutu Pelayanan Kesehatan. EGC. Jakarta

PT. Askes (2009) Persero. Info Askes Jakarta

Ratih (2010) Bauran Pemasaran. Alfabeta. Bandung

Sugiono (2007) Metode Penelitian Administrasi. Salemba Medika. Surabaya

Sulastomo (2003) Manajemen Kesehatan. Gramedia Pustaka Jakarta

Supriyanto (2003) Manajemen Mutu Pemasaran. UNAIR. Surabaya

Supriyanto (2009) Pemasaran Industri Jasa Kesehatan UNAIR. Surabaya

Supriyanto (2010) Manajemen Mutu. Universitas Airlangga Surabaya

Wijono (2008) Manajemen Mutu Rumah Sakit dan Kepuasan pasien. Duta Prima Airlangga Surabaya

Yazid (2008) Pemasaran Jasa. Ekonisia. Yogyakarata

Hasibuan, Malayu s,p. 2001. Manaejmen Sumber daya manusia. Bumi aksara. Jakarta

Ghozali,Imam. 2005. Aplikasi Analisis Multivariate dengan Program SPSS. Badan Penerbit Universitas Diponegoro. Semarang

Yazid. 2003. Pemasaran Jasa Konsep dan Implemantasi. EKONISIA Kampus Fakultas Ekonomi UII. Yogyakarta 